\title{
Der Alleskönner in Sachen Bonding
}

Mit iBOND ${ }^{\circledR}$ Universal stellt Heraeus Kulzer auf der IDS in Köln ein neues Bondingmaterial für die direkte und indirekte Restauration

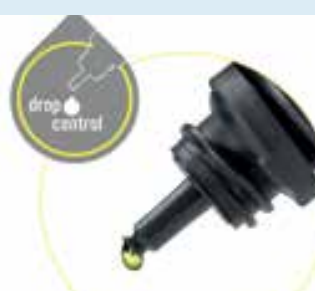
sowie intraorale Reparatur vor. Für das neue Produkt hat die Forschung \& Entwicklung bei Heraeus Kulzer mit Kollegen der Muttergesellschaft Mitsui Chemicals in Japan zusammengearbeitet. Das Ergebnis ist ein Adhäsiv mit einzigartiger Feuchtigkeitsregulierung: Aceton treibt das Wasser aus der Bonding-Schicht und unterstützt eine schnelle und gründliche Evaporation. Dieser Effekt vereinfacht das Lufttrocknen, reduziert die Techniksensitivität und erzeugt eine homogene Adhäsivschicht. Das Zusammenspiel der verschiedenen Komponenten ermöglicht die schnelle Verdunstung des Wassers, effektives Ätzen und eine gute Penetration in die Dentinkanälchen. Der neue Tropfer mit Tropfenkontrolle ermöglicht eine präzise Dosierung und erleichtert die tägliche Anwendung. Es eignet sich für alle Adhäsivtechniken und alle Oberflächen und ist kompatibel zu licht-, dual- und selbsthärtenden Materialien.

Halle 10.1 an Stand A010 - C019 